LUNG CANCER

\title{
Preliminary experience with a new method of endoscopic transbronchial real time ultrasound guided biopsy for diagnosis of mediastinal and hilar lesions
}

\author{
M Krasnik, P Vilmann, S S Larsen, G K Jacobsen
}

Thorax 2003;58:1083-1086

See end of article for authors' affiliations ......................

Correspondence to: Dr P Vilmann, Department of Surgical

Gastroenterology D,

Gentoffe University Hospital, Niels

Andersensvej 65, 2900

Hellerup, Denmark; pevi@

gentoftehosp.kbhamt.dk

Received 20February 2003

Accepted 26 August 2003
Background: The aim of the present study was to gain experience with a new method of endoscopic transbronchial ultrasonography with direct, real time guided fine needle aspiration biopsy (EBUS-FNA). Methods: EBUS-FNA was performed in 11 patients. Selection of the patients for EBUS-FNA was based on computed tomographic (CT) scanning in 10 patients and on positron emission tomography in one. The ultrasonic bronchoscope used was a prototype with an outer diameter of $6.9 \mathrm{~mm}$. The instrument has a small curved array transducer located in front of a $30^{\circ}$ oblique forward viewing optic lens and a biopsy channel of $2 \mathrm{~mm}$. The procedures were performed under general anaesthesia. EBUS-FNA was performed by direct transducer contact with the trachea or main bronchi with a prototype 22 gauge needle.

Results: A total of 15 lesions were punctured. No complications were experienced. Four lesions were targeted in region $10 \mathrm{~L}$, four in region $10 \mathrm{R}$, one in region $4 \mathrm{~L}$, three in region $4 \mathrm{R}$, one in region 1 , one in region 7 , and one in region $2 R$. The size of the lesions ranged from $7 \mathrm{~mm}$ to $80 \mathrm{~mm}$. EBUS-FNA identified malignant cells in 13 lesions and benign cells in two.

Conclusions: EBUS-FNA is a promising technique for lymph node staging of lung cancer as well as for the primary diagnosis of solid lesions located adjacent to the trachea and main bronchi and not accessible by other methods apart from surgical intervention.
$\mathrm{T}$ he prognosis of lung cancer is poor and closely related to the stage of disease. With the introduction of multimodality treatment, staging of this disease has become important. The aim of staging is therefore not only to evaluate the prognosis but also to decide on the proper treatment. Evaluation of cancer spread to the mediastinum, either as direct tumour invasion or as lymph node metastases, is one of the parameters in the staging system. Because conventional imaging methods such as computed tomographic (CT) scanning are inaccurate in diagnosing mediastinal lymph node metastases, tissue sampling-either as a histological or a cytological biopsy-is the most reliable. ${ }^{1-3}$ Several methods are available for obtaining biopsy specimens from mediastinal and hilar lesions including mediastinoscopy, CT guided biopsy, transbronchial fine needle aspiration, endoscopic ultrasound guided biopsy, anterior mediastinotomy, video assisted thoracoscopic surgery, and thoracotomy. However, each of these methods has its limitations. Transbronchial biopsy of mediastinal masses has become a routine procedure in the evaluation of patients suspected of having lung cancer. However, the sensitivity of this method has been reported to be variable, ${ }^{4}$ which may be because of the "blind" nature of the procedure. The development of new methods to improve the diagnosis of solid lesions including lymph nodes of the mediastinum and the hilar regions is desirable. We report a new method of endoscopic transbronchial ultrasonography with direct, real time guided fine needle aspiration biopsy (EBUS-FNA).

\section{METHODS}

EBUS-FNA was performed in 11 patients (seven men) of mean age 58 years (range 43-75). The selection of patients for EBUS-FNA was based on CT findings in 10 patients and on positron emission tomography (PET) in one. In three patients with an established diagnosis of lung cancer the CT scan had raised a suspicion of lymph node metastases in the mediastinum, and in four patients a suspicion of recurrent cancer with metastatic spread to the mediastinal or hilar regions (lung, breast, kidney, and laryngeal cancer). Another three patients had a mediastinal or hilar lesion of unknown origin demonstrated by CT scanning and one of these patients also had enlarged lymph nodes. In the last patient PET had raised a suspicion of breast cancer with mediastinal spread not shown by CT scanning. All patients with unknown primary lesions had undergone bronchoscopy with inconclusive results.

The flexible ultrasonic bronchoscope used was a prototype developed by Olympus (XBF-UC40P) (fig 1). The outer diameter of the insertion tube is $6.7 \mathrm{~mm}$, working length $550 \mathrm{~mm}$ (total lengths $870 \mathrm{~mm}$ ). The angulation range of the distal end of the endoscope is $160^{\circ}$ upward and $90^{\circ}$ downward. The instrument has a small curved linear array electronic transducer, length $10 \mathrm{~mm}$, located at the distal end of the endoscope in front of a $30^{\circ}$ oblique forward viewing fibreoptic lens (angle of view $80^{\circ}$ ). The diameter of the distal end of the endoscope with the transducer is $6.9 \mathrm{~mm}$, and the endoscope has a biopsy channel of $2 \mathrm{~mm}$. The ultrasonic frequency is $7.5 \mathrm{MHz}$ with a penetration depth of $5 \mathrm{~cm}$. The scanning direction is parallel to the longitudinal axis of the endoscope with a scanning angle of $50^{\circ}$ which enables full ultrasonic monitoring of a needle when inserted via the biopsy channel during scanning. The endoscope was connected to an Olympus ultrasound (US) processor (EU-C 60). Power Doppler facilities are available. A balloon which

Abbreviations: EBUS-FNA, endoscopic transbronchial ultrasonography with fine needle aspiration biopsy; EUS-FNA, endoscopic ultrasonography with fine needle aspiration biopsy; PET, positron emission tomography; NSCLC, non-small cell lung cancer; SCLC, small cell lung cancer 


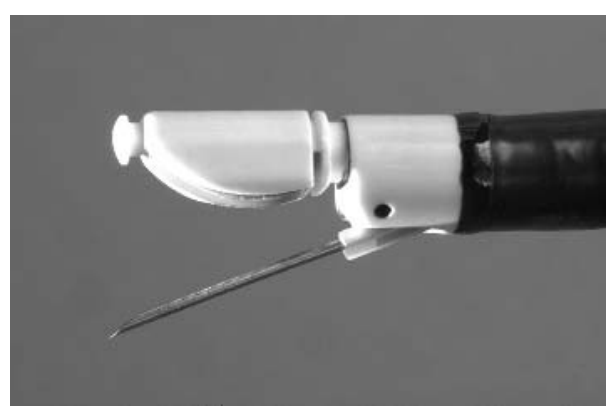

Figure 1 Distal end of the prototype fibreoptic ultrasonic bronchoscope (Olympus XBF-UC4OP) with an electronic linear array ultrasonic transducer and a needle introduced via the biopsy channel.

can be filled with water can be mounted around the transducer for better ultrasonic coupling with the bronchial wall.

\section{Procedure}

EBUS-FNA was performed with the patients under general anaesthesia. The ultrasonic bronchoscope was introduced via an endotracheal tube under visual control to the area of interest. EBUS-FNA was performed by direct transducer contact with the wall of the trachea or bronchus. When a lesion was outlined, a prototype 22 gauge full length steel needle (Olympus XNA-200C) was introduced via the biopsy channel of the endoscope. Power Doppler examination was used immediately before the biopsy in order to avoid unintended puncture of vessels between the wall of the bronchi and the lesion. Under real time ultrasonic guidance the needle was placed in the lesion (fig 2). Suction was applied with a syringe and the needle was moved back and forth inside the lesion. The specimen was expelled onto glass slides and smeared, air dried, and stained for cytological examination. The necessary number of passes was judged according to the macroscopic appearance of the aspirate. The location of the lesion was described according to the Mountain/Dresler classification ${ }^{3}$ of regional nodal stations for lung cancer staging.

\section{RESULTS}

A total of 15 lesions were punctured in 11 patients (table 1). No complications were experienced. Four lesions were targeted in region $10 \mathrm{~L}$, four in region $10 \mathrm{R}$, one in region $4 \mathrm{~L}$, three in region $4 \mathrm{R}$, one in region 1 , one in region 7 , and one in region $2 \mathrm{R}$. The size of the lesions ranged from $7 \mathrm{~mm}$ to $80 \mathrm{~mm}$. The number of needle passes ranged from 1 to 3 (mean 2.3). EBUS-FNA identified malignant cells in 13 lesions and benign cells in two. Non-small cell lung cancer (NSCLC) was diagnosed in four patients, adenocarcinomas in one, unspecified carcinoma in two, and small cell carcinoma, renal carcinoma of clear cell type, and squamous cell carcinoma each in one patient. The two lesions with benign cytology were localised as follows:

- Region 10R in a patient with NSCLC in whom the EBUSFNA from region 4L demonstrated malignancy. Mediastinoscopy was negative.

- Region 10L in a patient with a positive PET in the mediastinum and in the right breast. Mediastinoscopy was negative.

Both lesions sampled were lymph nodes below $10 \mathrm{~mm}$ in size.

Based on the diagnosis obtained by EBUS-FNA, eight patients received chemotherapy, one patient had a pneumonectomy performed, one patient a mastectomy, and in the last patient an explorative thoracotomy was performed which showed inoperable oesophageal cancer.

We did experience a few problems with difficult needle penetration through the anterior tracheal wall due to the hard cartilage rings. In such cases we had to withdraw the transducer from the tracheal wall and position the needle tip in the adjacent intercartilage space before repositioning the transducer.

\section{DISCUSSION}

The prognosis of lung cancer is closely related to the stage of the disease. Evaluation of cancer spread to the mediastinum, either as direct tumour invasion or as lymph node metastases, is important in order to plan the therapeutic strategy. Other cancers also have a tendency to metastasise to the mediastinum and hilar regions and in these patients it is crucial to confirm this suspicion by a correct diagnosis. Conventional imaging methods such as CT scanning and PET alone are unreliable in the diagnosis of mediastinal lymph node metastases because of false positive or false negative diagnoses. ${ }^{4-6}$ A diagnosis of lung cancer may be difficult to obtain by bronchoscopy and, in such cases, a mediastinal lesion may be seen by CT scanning.

In order to obtain tissue for pathological evaluation, mediastinoscopy has hitherto been the method of choice. However, the procedure has a complication rate of $2-3 \%$ and, in up to $10 \%$ of patients who undergo surgery after a negative mediastinoscopy, the surgical procedure results in explorative thoracotomy without resection of the tumour. ${ }^{7}$ A new minimally invasive procedure which can improve the mediastinal evaluation is therefore desirable in order to avoid unnecessary explorative thoracotomies.

Endobronchial ultrasound probes have been developed for evaluation of the depth of invasion of malignant tumours in the central and peripheral bronchi as well as for evaluation of lymph nodes located in the mediastinum in patients with lung cancer. Until recently the ultrasound probes have been mechanical radial scanning mini-probes which can be introduced via the working channel of a flexible bronchoscope creating a cross sectional image of the bronchial wall and immediate surroundings. Improved accuracy of T staging has been achieved with these probes as a result of visualisation of tumour invasion depth through the bronchial wall. ${ }^{8}$ Improved $\mathrm{N}$ staging has also been reported as a result of more precise targeting of lymph nodes during the transbronchial fine needle biopsy procedure performed immediately after ultrasonic localisation. ${ }^{10}{ }^{11}$ However, it would be desirable to be able to monitor the biopsy procedure as is done routinely by transcutaneous ultrasound guided biopsy or by endoscopic ultrasound guided biopsy (EUSFNA).

EUS-FNA performed via the oesophagus has been shown to be valuable in staging lung cancer and for the primary diagnosis of lesions suspected of malignancy, especially in the posterior and lower part of the mediastinum. ${ }^{14}$ However, the region anterior to the trachea and main bronchi cannot be reached by EUS-FNA. Until recently it was impossible to produce an ultrasonic bronchoscope with a biopsy channel and a linear scanning ultrasonic transducer incorporated at the tip of the instrument of an acceptable size to fit into the trachea and main bronchi. We have tested a prototype ultrasonic bronchoscope in 11 patients in whom most other procedures failed to show the true nature of the disease. All biopsies were performed with an instrument developed for EUS-FNA ${ }^{12}$ but with a modified needle and needle sheath. The EBUS-FNA was performed with complete ultrasonic control of the needle insertion in all cases. The aspirated material obtained from the different types of malignant 

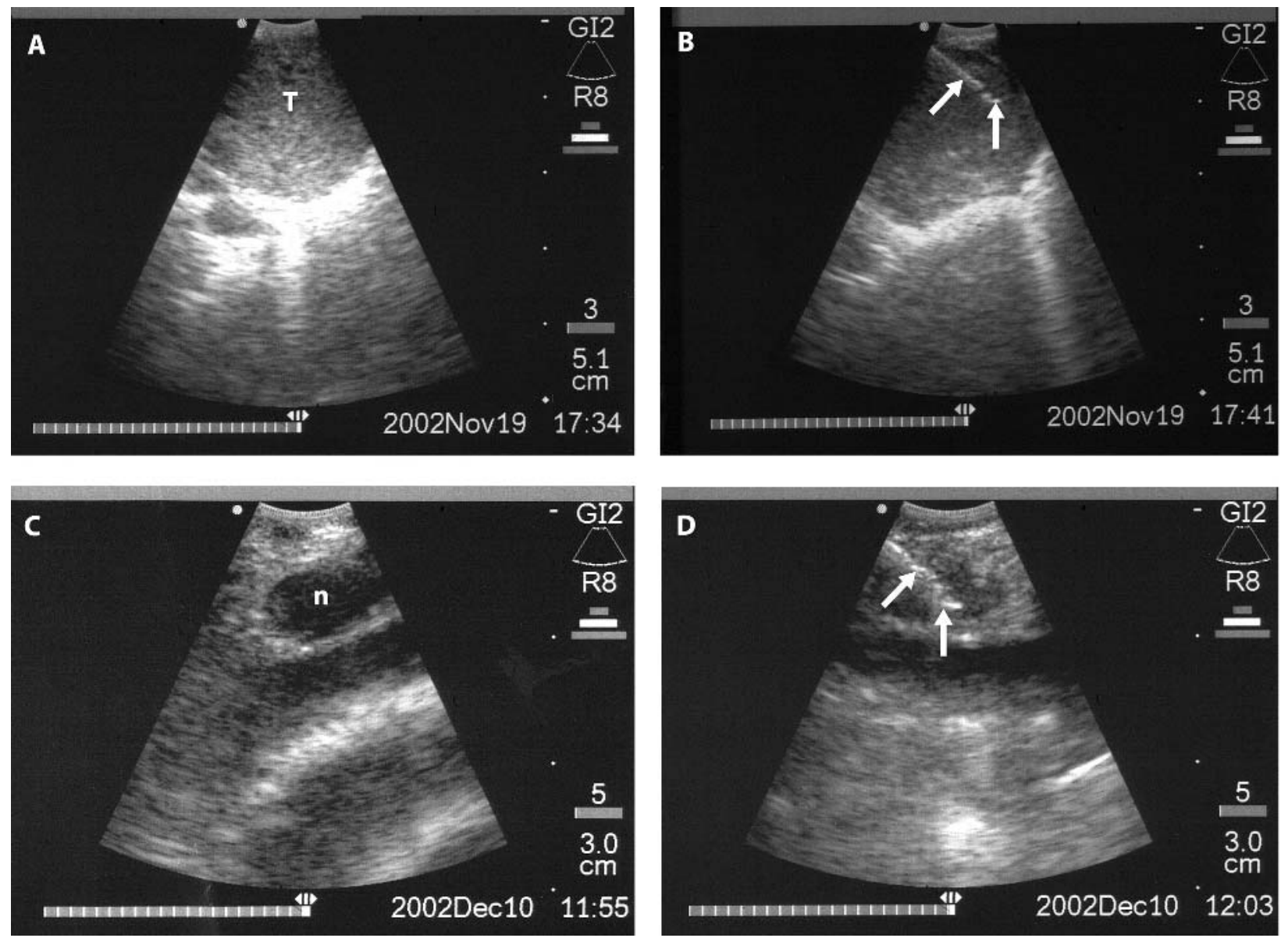

Figure 2 (A) Endoscopic transbronchial ultrasound image demonstrating an echo poor hilar mass (T) located in front of the right main bronchus (region 1OR). (B) Endoscopic transbronchial ultrasound image demonstrating an EBUS-FNA from the same mass as above. Reflections from the needle inside the lesion are indicated by arrows. (C) Endoscopic transbronchial ultrasound image demonstrating an echo poor lymph node (n) located in the upper mediastinum in front of the trachea (region 1). (D) Endoscopic transbronchial ultrasound image demonstrating an EBUS-FNA from the same lymph node as above. Reflections from the needle inside the lesion are indicated by arrows.

lesions was diagnostic in all cases and the diagnosis had a major impact on patient management. Important clinical problems were resolved in all the patients which might otherwise have been difficult or even impossible to manage without more invasive methods such as mediastinoscopy, thoracoscopy or even open thoracotomy. If EUS-FNA was

\begin{tabular}{|c|c|c|c|}
\hline Patient & $\begin{array}{l}\text { Location of } \\
\text { lesion targeted }\end{array}$ & $\begin{array}{l}\text { Cytology } \\
\text { results }\end{array}$ & Treatment \\
\hline $\begin{array}{l}\text { Unknown hilar lesion, suspicion of } \\
\text { recurrent renal cancer }\end{array}$ & $10 \mathrm{~L}$ & Clear cell carcinoma & Chemotherapy \\
\hline Unknown mediastinal mass & $10 \mathrm{~L}$ & $\begin{array}{l}\text { Squamous cell } \\
\text { carcinoma }\end{array}$ & $\begin{array}{l}\text { Explorative surgery } \\
\text { (inoperable oesophageal cancer) }\end{array}$ \\
\hline Right sided lung cancer & 10R & NSCLC & Chemotherapy \\
\hline Right sided lung cancer & $\begin{array}{l}10 \mathrm{R} \\
4 \mathrm{~L}\end{array}$ & $\begin{array}{l}\text { Benign } \\
\text { NSCLC }\end{array}$ & Chemotherapy \\
\hline Recurrent lung cancer & $10 \mathrm{~L}$ & NSCLC & Chemotherapy \\
\hline $\begin{array}{l}\text { Unknown right sided mediastinal } \\
\text { lesion }\end{array}$ & $4 R$ & Carcinoma & Pneumonectomy \\
\hline Right sided lung cancer & $\begin{array}{l}10 R \\
4 R\end{array}$ & $\begin{array}{l}\text { NSCLC } \\
\text { NSCLC }\end{array}$ & Chemotherapy \\
\hline Unknown mediastinal lesion & $10 \mathrm{~L}$ & Benign & Mastectomy \\
\hline Right sided lung cancer & $\begin{array}{l}10 \mathrm{~L} \\
4 \mathrm{R}\end{array}$ & $\begin{array}{l}\text { SCLC } \\
\text { SCLC }\end{array}$ & Chemotherapy \\
\hline $\begin{array}{l}\text { Cava superior syndrome (unknown } \\
\text { nature) }\end{array}$ & $2 \mathrm{R}$ & Adenocarcinoma & Chemotherapy \\
\hline Left sided lung cancer & $\begin{array}{l}1 \\
7\end{array}$ & $\begin{array}{l}\text { Carcinoma } \\
\text { Carcinoma }\end{array}$ & Chemotherapy \\
\hline
\end{tabular}


performed routinely in all patients, this might have resolved some of the questions. However, lesions targeted anterior to the trachea and the main bronchi would not have been possible to diagnose by EUS-FNA. The exact place of these two methods in the diagnostic armamentarium must await further studies. The patients were selected based on findings by CT scanning and, in one patient, by PET. Several of the lesions were relatively large and might have been reached by "blind" transbronchial fine needle aspiration or mediastinoscopy. However, it should be noted that three of the lymph nodes targeted were only $7 \mathrm{~mm}, 8 \mathrm{~mm}$ and $15 \mathrm{~mm}$ in size, and malignant cells were collected from two of these. In our experience, these lymph nodes would have been difficult or impossible to hit using "blind" methods.

The main aim of our study was to see whether EBUS-FNA was possible and, if so, to gain experience with this method. The procedure was therefore performed in patients under general anaesthesia. It is our intention to perform the procedure under local analgesia as soon as the entire technique has been fully established. More experience with this new method is needed and studies comparing conventional transbronchial fine needle aspiration, EUS-FNA, and mediastinoscopy with EBUS-FNA should be initiated. However, we believe that the combination of EUS-FNA and EBUS-FNA will be able to replace more invasive methods in the evaluation of mediastinal and hilar lesions, possibly with improved sensitivity.

In conclusion, EBUS-FNA is a promising technique for lymph node staging of lung cancer and for the primary diagnosis of solid lesions located adjacent to the main bronchi and the trachea. More experience and further studies are needed to evaluate the true value of this method.
Authors' affiliations

M Krasnik, P Vilmann, S S Larsen, G K Jacobsen, Department of Cardiothoracic Surgery R and Department of Surgical Gastroenterology D, Gentofte University Hospital, Niels Andersens Vej 65, 2900 Hellerup, Denmark

\section{REFERENCES}

1 Larsen SS, Krasnik M, Vilmann P, et al. Endoscopic ultrasound guided fine needle biopsy of mediastinal lesions has a major impact on patient management in lung cancer disease. Thorax 2002;57:98-103.

2 Harrow EM, Oldenburg FA, Lingenfelter MS, et al. Transbronchial needle aspiration in clinical practice. Chest 1989;96:1268-72.

3 Mountain CF, Dresler CM. Regional lymph node classification for lung cancer staging. Chest 1997;111:1486-7.

4 Wiersema MJ, Vazquez-Sequeiros E, Wiersema LM. Evaluation of mediastinal lymphadenopathy with endoscopic US-guided fine-needle aspiration biopsy. Radiology $2001 ; 219: 252-7$.

5 Kamiyoshihara M, Kawashima O, Ishikawa S, et al. Mediastinal lymph node evaluation by computer tomographic scan in lung cancer. J Cardiovasc Surg 2001;42:119-24.

6 Pieterman RM, van Putten JW, Meuzelaar JJ, et al. Preoperative staging of non-small-cell lung cancer with positron-emission tomography. N Engl J Med 2000:343:254-61.

7 Shields TW. Surgical treatment of non-small-cell bronchial carcinoma. In: Shields TW, ed. General thoracic surgery. Volume 2. 4th ed. New York: Williams and Wilkins, 1994:1159-69.

8 Kurimoto N, Murayama M, Yoshioka S, et al. Assessment of usefulness of endobronchial ultrasonography in determination of depth of tracheobronchial tumor invasion. Chest 1999;115:1500-6.

9 Herth F, Becker HD, Manegold C, et al. Endobronchial ultrasound: assessment of a new diagnostic tool in bronchoscopy for staging of lung cancer. Onkologie 2001;24:151-4.

10 Shannon JJ, Bude RO, Orens JB, et al. Endobronchial ultrasound guided needle aspiration of mediastinal adenopathy. Am J Respir Crit Care Med 1996; 153:1424-30.

11 Okamoto H, Watanabe K, Nagatomo A, et al. Endobronchial ultrasonography for mediastinal and hilar lymph node metastases of lung cancer. Chest 2002;121:1498-506.

12 Vilmann P, Hancke S. A new biopsy handle instrument for endoscopic ultrasound guided biopsy. Gastrointest Endosc 1996;43:238-42. 